Okajima, Kenji; Magara, N.; lida, Toshiaki

Reexamination of Creep Theory in the Foundation of Weirs by Model Experiments and Elasto-Plastic FEM

Verfügbar unter / Available at:

https://hdl.handle.net/20.500.11970/100269

Vorgeschlagene Zitierweise / Suggested citation:

Okajima, Kenji; Magara, N.; lida, Toshiaki (2010): Reexamination of Creep Theory in the Foundation of Weirs by Model Experiments and Elasto-Plastic FEM. In: Burns, Susan E.; Bhatia, Shobha K.; Avila, Catherine M. C.; Hunt, Beatrice E. (Hg.): Proceedings 5th International Conference on Scour and Erosion (ICSE-5), November 7-10, 2010, San Francisco, USA. Reston, Va.: American Society of Civil Engineers. S. 560-569. 


\title{
Reexamination of Creep Theory in the Foundation of Weirs by Model Experiments and Elasto-Plastic FEM
}

\author{
K. Okajima ${ }^{1}$, N. Magara ${ }^{1}$ and T. Iida ${ }^{1}$
}

\begin{abstract}
${ }^{1}$ Laboratory of Water Environmental Engineering, Department of Biological and Environmental Engineering, Graduate School of Agricultural and Life Sciences, The University of Tokyo, Zip code 113-8657, Tokyo, Bunkyo-ku Yayoi 1-1-1; PH(+81)3-5841-5349; email: aokajim@mail.ecc.u-tokyo.ac.jp
\end{abstract}

\begin{abstract}
Creep flow theories that are Bligh's and Lane's equation have been used as the safety criteria against piping under foundation of weirs. These methods were reexamined by model experiments and finite element analyses in this study. These model experiments were carried out in six patterns and had same creep length by changing the installation position and length of cut-off wall. These critical water heads of model experiments were different from each pattern. It was clear that creep flow theories were not able to predict these differences. Our FEM predicted these critical water heads of model experiments. Maximum shear strain contour line by our finite element analysis indicated that shear strain concentrated in similar soil mass as Terzaghi assumed in the seepage failure equation. It was suggested that Terzaghi's method was more effective than the creep theory to calculate the critical water head if the soil mass was defined properly.
\end{abstract}

\section{INTRODUCTION}

Creep flow theories are applied to the design criteria against piping of foundation of a weir. Bligh's creep flow theory was developed as the empirical equation for the design of floating type weirs in permeable layer through many experiences in 1910 (Bligh). After suggestion of this theory it was indicated that vertical sections of the creep length contribute more to reduce the danger of piping than horizontal sections of the length. In the response to this, Lane (1935) suggested the weighted creep flow theory. These creep flow theories were based on the assumption that the cause of piping was erosion along the contact surface between soils and weir.

The purpose of this study is the reexamination of these practical safety criteria 
against seepage failure. We conducted a series of model experiments, and then evaluated these practical safety criteria and the validity of the elasto-plastic FEM by applying to the experiments.

\section{CREEP FLOW THEORIES}

To prevent piping at the down-stream side of a weir, practical manuals indicate that a safe creep length have to be ensured under the surface of the weir and along the side of the weir. The creep length to be ensured must be larger than the values calculated by two methods.

The first method is Bligh's method.

$$
L_{B} \geq C_{B} \Delta H
$$

Where $L_{B}$ is the creep length that is measured along the bottom face of the weir, $C_{B}$ is Bligh's creep ratio which varies depending on the type of the foundation soil, and $\Delta H$ is the water head. For example the fine sand $C_{B}$ is 15 . The critical head is $\Delta H_{C B}$ when $L_{B}=C_{B} \Delta H_{C B}$.

The second method is Lane's method.

$$
L_{L} \geq C_{L} \Delta H
$$

Where $L_{L}$ is the weighted creep length.

$$
L_{L}=\sum l_{v}+k_{v} / k_{h} \sum l_{h}
$$

Where, $l_{v}$ is the creep length of vertical direction (inclination angle of more than 45 degrees), $l_{h}$ is the creep length of horizontal direction (inclination angle of lower than 45 degrees). $k_{v}$ is the vertical coefficient of permeability and $k_{v}$ is the horizontal coefficient of permeability. However, $k_{v} / k_{h}$ has been used $1 / 3$ customarily. $C_{L}$ is Lane's creep ratio which varies depending on the type of the foundation soils. For example the fine sand $C_{L}$ is 7.0. $\Delta H$ is the water head. The critical head is $\Delta H_{C L}$, when $L_{L}=C_{L} \Delta H_{C L}$. 


\section{MODEL EXPERIMENTS AND REEXAMINATION OF CREEP FLOW THEORIES}

\section{Layout of Model Experiments}

The experimental apparatus was consisted of a glass-walled sand box. The size was $1000 \mathrm{~mm}$ long, $500 \mathrm{~mm}$ high and $200 \mathrm{~mm}$ wide. The permeable layers in these model experiments were made by using clean sand. The sand was the Toyoura sand with a specific gravity of 2.64 , a mean diameter $\left(D_{50}\right)$ of $0.16 \mathrm{~mm}$ and a uniformity coefficient of 1.46. The weir was made of rigid acrylic plates. The weir was fixed to sand box and was sealed by silicon rubber and silicon adhesion bond to prevent water and sand from spilling out. The sandpaper was pasted on the bottom and side of the weir to prevent roofing. The cut-off wall was made of aluminum plate. The sand layers were prepared by pouring dry sand using hopper into stored water and deleting air during the soil particle falling. The high density of the sand layers was obtained: the relative density was about $85 \%$.

After setting up the water levels of both upstream and downstream side equal, the downstream water level was lowered incrementally ( $5 \mathrm{~mm}$ after an hour). The deformation of the sand layer was measured. When piping or boiling occurred, the water head was defined to attain the critical water head.

The data of a series of model experiments are indicated in Figure2. All patterns had same creep length in which Bligh's creep length is $180 \mathrm{~mm}$ and Lane's creep length is $123 \mathrm{~mm}$. These data were obtained by conducting 2 or 3 times in each experiment. These experiments are divided into 3 groups (Figure1). The first group was named "Depth group" to change penetration depth of the weir: Weir1, Weir2 and Weir3. From these experiments we can evaluate the influence of the depth of the weir for piping. The second group was named "Position group" to change the position of a cut-off wall: Weir4, Wei3 and Weir5. From these experiments we can evaluate the influence of the position of the cut-off wall for piping. The third group was named "Two cut-off group" to change the position and length of two cut-off walls: Weir6 and Weir7. From these experiments we can evaluate the influence of the position of the cut-off wall for piping.

\section{Results of Model Experiments}

Table1 shows results of model experiments that are relative density (\%), critical water head, the kind of seepage failure (Piping or Boiling) and average of critical water head. Piping was observed in some patterns of model experiments. The 
heaving was observed because sand ground in down-stream side deformed. Relative densities were about $85 \%$ from $81.2 \%$ to $88.9 \%$. Critical water heads in each pattern were similar water heads. In these model experiments the reproducibility was observed.

These model experiments had same creep length. Bligh's and Lane's creep flow theories predict a critical water head with patterns. However, each critical water head was different from the other pattern. The result indicated that creep flow theories were not able to predict the critical water head. Discussions of each groups described later.

Table 1 Results of model experiments
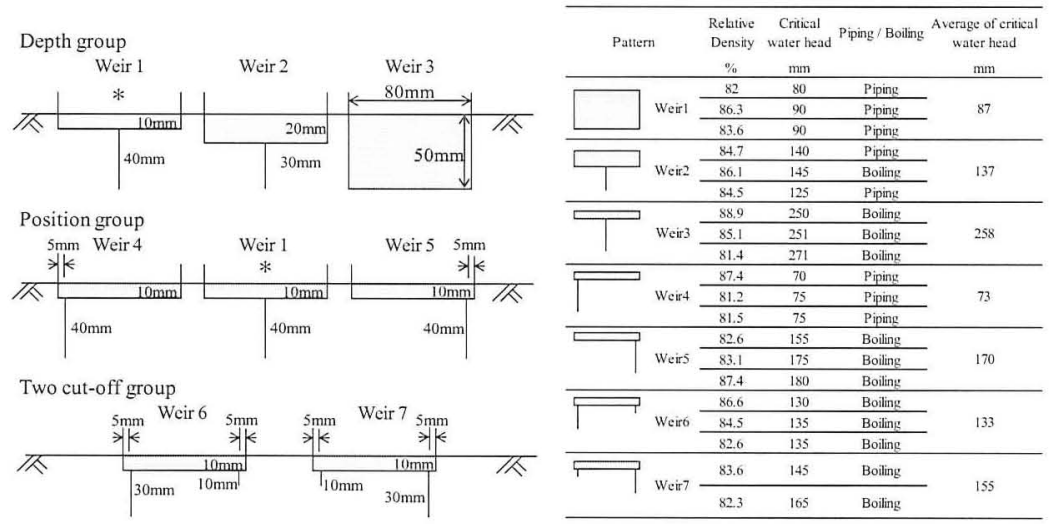

Figure 1 Patterns of model experiments

\section{SEEPAGE FAILURE ANALYSES BY ELASTO-PLASTIC FEM}

In this study the finite element analysis consisted of two steps. The first step is the seepage flow analysis by FEM. The second is the seepage failure analysis by the elasto-plastic FEM to input effective stress regarding the seepage force as the external force.

\section{Constitutive model of the elasto-plastic model}

The finite element analysis employs the elasto-plastic constitutive equations with a non-associated flow rule and strain hardening-softening. The constitutive equations based on the yield function of Mohr-Coulomb and the plastic potential function of Drucker-Prager. The finite element is 4-noded iso-parametric element 
with one point integration. The explicit dynamic relaxation method combined with the generalized return-mapping algorithm is applied. The elasto-plastic constitutive relations including the effect of the shear band are employed.

A simplified and generalized version of mesh size-dependent softening modulus method (Tanaka and Kawamoto, 1989) is used in this study. A material model for a real granular material (i.e., Toyoura sand) with a high angle of internal friction is used with the features of nonlinear pre-peak, pressure-sensitivity of the deformation and strength characteristics of sand, non-associated flow characteristics, post-peak strain softening, and strain-localization into a shear band with a specific width (Tatsuoka et al., 1991; Siddiquee, 1999). The material model will be briefly described in this section.

\section{Input Parameter and FEM mesh}

In the elasto-plastic finite element analysis, the material constants of Toyoura sand are as follow: relative density $=88 \%$, residual friction angle $\left(\phi_{r}\right)=33$ degree The calibration of the other elasto-plastic parameter of air-dried Toyoura sand in the elasto-plastic constitutive model was performed using the plane strain compression tests by Tatsuoka et al (1986). The analysis was performed using a series of finite element mesh of each model experiment, as shown in Figure2. Elements bordering on the weir were boundary elements and the friction was set to be equal to the friction between sand and weir in these elements.

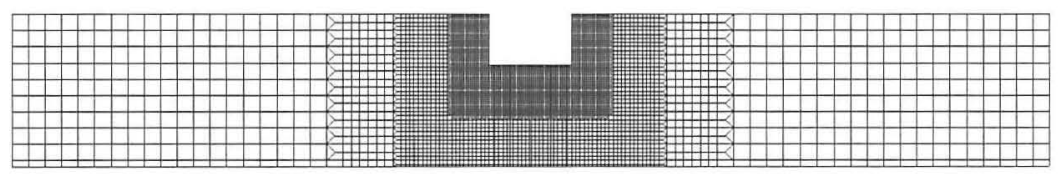

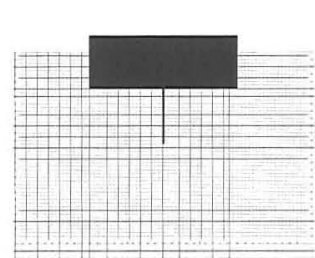

(a) Weir2 mesh

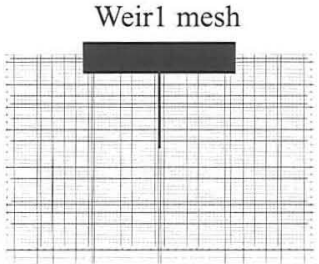

(b) Weir3 mesh

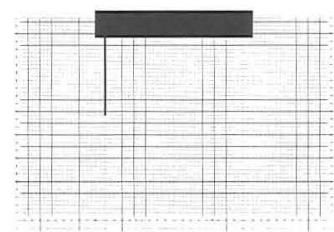

(c) Weir4 mesh 


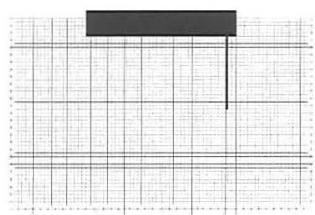

(e) Weir5 mesh

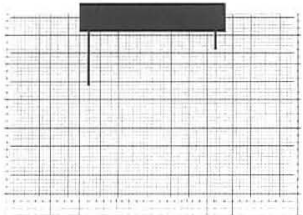

(a) Weir6 mesh

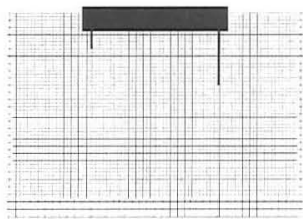

(b) Weir7 mesh

Figure 2 FEM mesh

\section{RESULT AND DISCUSSION}

\section{Critical water head}

Result of model experiments and FEM in each groups are discussed about the effectiveness of FEM and the tendency of seepage failure of foundation of the weir. Figure 3 indicates the critical water head of Position group. The critical water head gradually increases with the moving to the downstream end of the weir in Position group which has same creep length. Results of FEM predicted each critical water head well. Figure 4 indicates the critical water head of Depth group. The critical water head gradually increases with the increasing the penetration depth of the weir in Depth group which has same creep length. Results of FEM predicted each critical water head well. Figure 5 indicates the critical water head of Two cut-off group. The critical water head varies with the number and length of cut-off walls though these critical water head was near without the point of longer cut-off wall. Results of FEM predicted each critical water head well. Results of FEM which penetration depth of weir was $10 \mathrm{~mm}$ and the cut-off wall was set at upstream side or middle of the length of weir were computed higher than results of model experiments (Weir1 and Weir4). The reason is considered that the continuum model might not hold true when number of particle of sand (the average particle side is $0.16 \mathrm{~mm}$ ) was about 60 at the downstream edge of the weir. Result of FEM which penetration depth of weir was $50 \mathrm{~mm}$ was computed lower than results of model experiment (Weir3). The reason was considered that the friction of the side glass wall influenced the water head of boiling because it was observed that larger sand mass moved during the boiling in the model experiments of Weir3. These discussions indicated that our FEM was effective analysis to compute the critical water head.

\section{Maximum shear strain}

Our elasto- plastic FEM has the frictional hardening-softening functions. 
When the maximum shear strain reaches 0.1 , the frictional function changes from hardening regime to softening regime. At that time the shear band develops in these elements. Figure6 indicates that the observed shear band in model experiment at water head $180 \mathrm{~mm}$ and computed maximum shear strain distribution by FEM at water head $170 \mathrm{~mm}$. The observed shear band is showed by broken line in the picture. When the shear band was compared with concentration area of the maximum shear strain, it is clear that our FEM is able to predict the position and the tilt of the shear band well. This result indicated that our FEM was able to predict the deformation by seepage failure. So we discussed the mechanism of seepage failure with these maximum shear strain distribution by our FEM.

Figure7 indicates maximum shear strain distributions at the critical water head of Weir1, Weir2, Weir3 and Weir4. It is indicated that the mechanism to change the critical water head of Depth group is expanding of concentration area of maximum shear strain from Figure7 (a), (b) and (d). It is indicated that the mechanism to change the critical water head of Position group is expanding of concentration area of maximum shear strain from Figure6 and Figure7 (d) when the cut-off wall approaches the downstream edge of weir. However the concentration areas of Figure7(c) and (d) is very similar without the position of the cut-off wall. The difference of the critical water head between Weir 4 and Weir1 causes the seepage force by seepage flow.

These mechanisms of seepage failure indicated that Terzaghi's method in the cut-off pile was possible to predict the critical water head in the weir.

\section{Application of Terzaghi's method}

Terzaghi's method is the most famous method of a critical hydraulic gradient. Originally, Terzaghi's method was developed to be applied to a safety criterion for sheet pile piping. This method was formulated based on experimental model tests and its effectiveness was confirmed by many sheet pile model tests.In Terzaghi's method, a piping occurs when the submerged weight of the soil prism on the down-stream side of the sheet pile equals the heaving force by excess hydrostatic pressure. In the formulation Terzaghi defined that the size of the prism was $D \times D / 2$ in the two dimensional condition when the penetration depth is $D$.

In this study we decided that the penetration depth $D$ is the depth of downstream edge of the weir. Figure 8 indicates the result of application of Terzaghi's method to the weir. Terzaghi's method was very good prediction of the critical water head. It was suggested that Terzaghi's method was more effective than the creep 
theory to calculate the critical water head in the seepage failure of the weir.

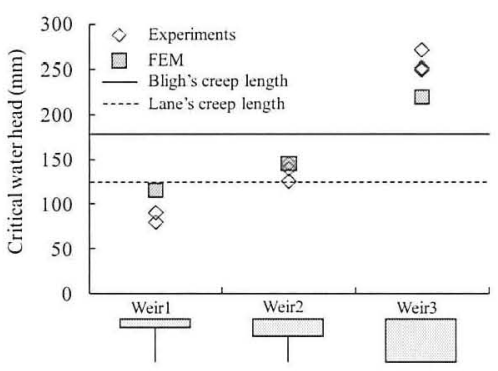

Figure 3 Critical water head of Position group

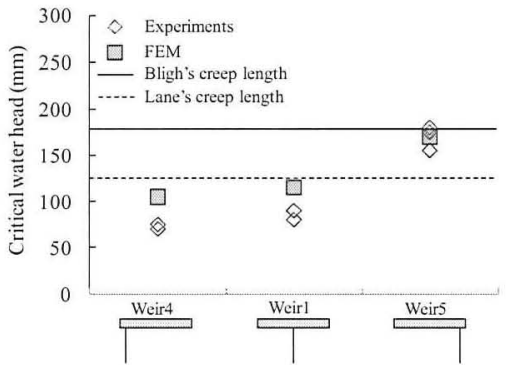

Figure 4 Critical water head of Depth group

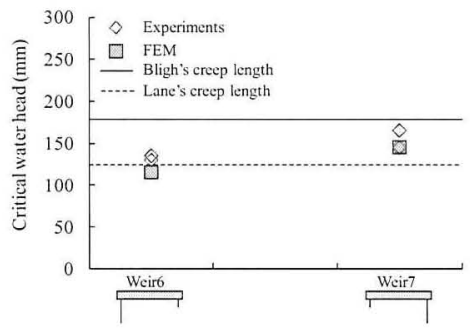

Figure 5 Critical water head of Two cut-off group

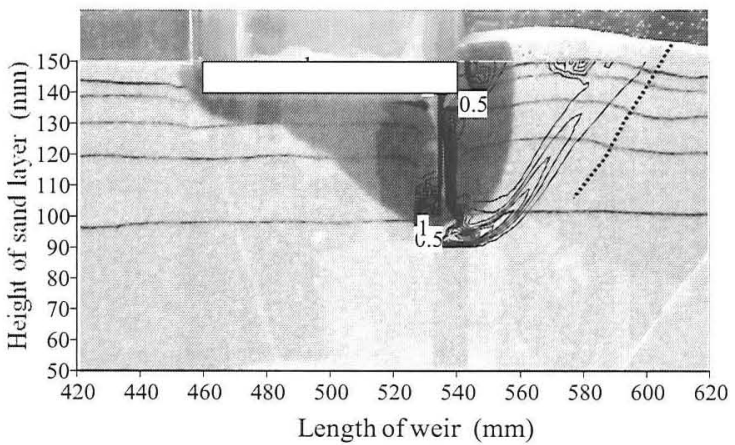

Figure 6 Shear band in model experiment at water head $180 \mathrm{~mm}$ and maximum shear strain distribution at water head $170 \mathrm{~mm}$ 


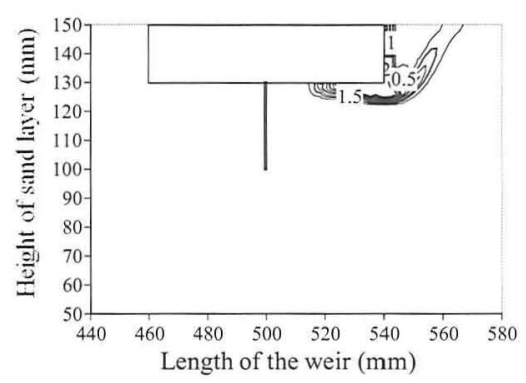

(a)Maximum shear strain distribution at water head $140 \mathrm{~mm}$ (Weir2)

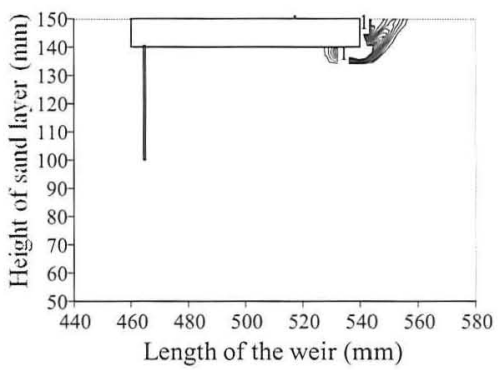

(c)Maximum shear strain distribution at water head $105 \mathrm{~mm}$ (Weir4)

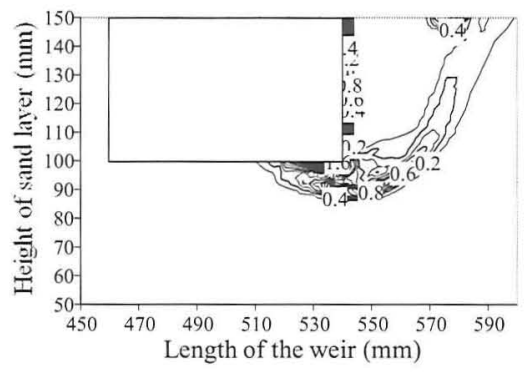

(b)Maximum shear strain distribution at water head $230 \mathrm{~mm}$ (Weir3)

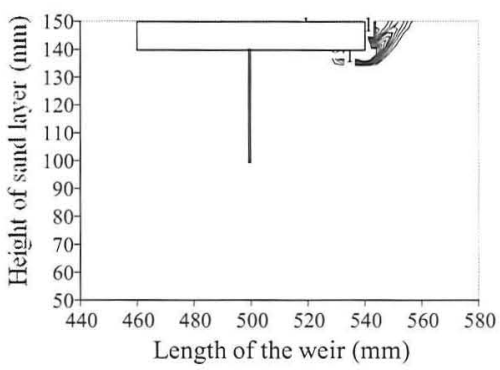

(d)Maximum shear strain distribution at water head $115 \mathrm{~mm}$ (Weir1)

Figure 7 Maximum shear strain distribution of elasto-plastic FEM

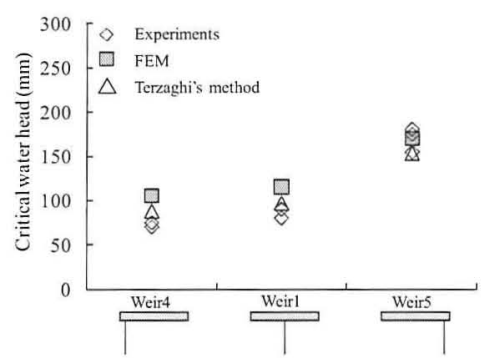

(a) Critical water head of Position group

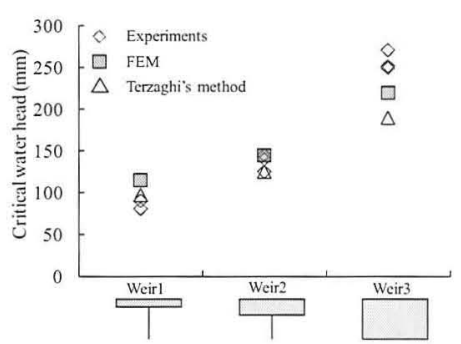

(b) Critical water head of Depth group

Figure 8 Critical water head in applying Terzaghi's method 


\section{CONCLUSION}

Creep flow theories were reexamined by model six patterns experiments and finite element analyses that had same creep length by changing the installation position and length of cut-off wall in this study. These critical water heads of model experiments were different from each pattern. It was clear that creep flow theories were not able to predict the critical water head. Our FEM predicted these critical water heads of model experiments. Maximum shear strain contour line by our finite element analysis indicated that shear strain concentrated in similar soil mass as Terzaghi assumed in the seepage failure equation. It was suggested that Terzaghi's method was more effective than the creep theory to calculate the critical water head if the soil mass was defined properly.

\section{REFERENCES}

Bligh, W. G. (1910) "The practical design of irrigation works", London Constable, 162-205

Lane, E.W. (1935) "Security from Under seepage Masonry Dams on Earth Foundations", Trans. ASCE, 100, 1234-1351,

Tanaka, T and Verruijt, A (1999) "Seepage failure of sand behind sheet piles - The mechanism and practical approach to analyze-", Soils and Foundations, 39(3), 27-35

Tanaka, T. and Kawamoto, O. (1988) "Three dimensional finite element collapse analysis for foundations and slopes using dynamic relaxation", Proc. of Numer. Meth. in Geomech., 1213-1218,

Tatsuoka, F., Siddiquee, M. S. A, Park, C. S., Sakamoto, M. and Abe, F. (1993) "Modeling Stress-Strain Relations of Sand", Soils and Foundations, 33(2), 60-81

Terzaghi, K. and Peck, R. B. (1948) "Soil Mechanics IN Engineering Practice", John Wiley and Sons, 218-233 